\title{
A study on pearlescent performance of green black coating layer on micron glass
}

\author{
Ji-Cong Pei ${ }^{1}$, Yan Huang ${ }^{\dagger,},{ }^{1}$, Xiao-Yu Han ${ }^{1}$, \\ Yu-Xiang Yang ${ }^{\dagger, 1}$ and Xiang-Nong Liu ${ }^{2}$ \\ ${ }^{I}$ School of Chemistry and Molecular Engineering, \\ East China University of Science and Technology, \\ Shanghai 200237, China \\ ${ }^{2}$ Testing Center, Yangzhou University, \\ Yangzhou 225009, China \\ ${ }^{\dagger}$ E-mail: huangyan@ecust.edu.cn, yxyang@ecust.edu.cn \\ www.ecust.edu.ch
}

\begin{abstract}
Preparation of pearly green black pigment (micron glass/nano- $\mathrm{Fe}_{3} \mathrm{O}_{4}$ ) can be carried out by a green process: eroding the micron dimension glass first, then second co-precipitating ferrous and ferric ions on the eroded substrate, which should minimize long and shortterm impacts on the environment. The pearly green black pigments were characterized by XRD, HRSEM and color measurement, and the content of $\mathrm{Fe}_{3} \mathrm{O}_{4}$ coating layer can be calculated by using external standard calibration method.

Keywords: Micron Glass; $\mathrm{Fe}_{3} \mathrm{O}_{4}$ Coated Layer; Green Pearlescent Pigment; Minimize Impacts on the Environment.
\end{abstract}

\section{Introduction}

As black perspectives for a green future, $\mathrm{Fe}_{3} \mathrm{O}_{4}$ is an important ferrite with a cubic inverse spinel structure, which makes $\mathrm{Fe}_{3} \mathrm{O}_{4}$ an important semimetal material [1]. A hypothesis is proposed which suggests pearlescent pigments with high performance could be prepared using micron dimension glass as substrate in place of the mica to develop third-generation pearlescent pigments for obtain more pearlescent luster. So in this paper, the micron dimension glass was first pretreated with sodium hydroxide solution and KF solution under ultrasonic treatment in proper order. Then the pearlescent pigment was prepared by coprecipitation of $\mathrm{Fe}_{3} \mathrm{O}_{4}$ coating on the surface of eroded micron dimension glass according to our previous work [2], the final product was filtrated and washed, following dried at $60{ }^{\circ} \mathrm{C}$, and calcined for 3 hours at $350{ }^{\circ} \mathrm{C}$ under nitrogen in tube furnace. The results showed typically spherical micro-sized particles are generally obtained, which can be considered as green, black natural pigmen. 


\section{Experimental}

\subsection{Coating of $\mathrm{Nano}_{-} \mathrm{Fe}_{3} \mathrm{O}_{4}$ on micron glass}

(1) Micron glass was placed into three small plastic beakers $(10 \mathrm{~g}$ each), and washed under ultrasonic treatment in $\mathrm{NaOH}$ solution $(0.5 \mathrm{~mol} / \mathrm{l})$ for $5 \mathrm{~min}, 15 \mathrm{~min}$, 20min, respectively, and then filtrated, washed and dried at $80{ }^{\circ} \mathrm{C}$.

(2) After surface dirt was removed from micron glass powder in the same way, KF solution $(80 \mathrm{ml}, 1 \mathrm{~mol} / \mathrm{l})$ and concentrated sulfuric acid (3ml) were added into the six plastic beakers each containing $10 \mathrm{~g}$ micron glass. Then the mixtures were stirred for $2 \mathrm{~min}, 5 \mathrm{~min}, 8 \mathrm{~min}, 8 \mathrm{~min}, 8 \mathrm{~min}$ and $8 \mathrm{~min}$ respectively. The eroded micron glass was filtrated, washed and dried at $80^{\circ} \mathrm{C}$, and kept until use.

(3) Synthesis of Micron Glass/Nano- $\mathrm{Fe}_{3} \mathrm{O}_{4}$

The suspension of boiled deionized water and $10 \mathrm{~g}$ eroded micron glass powder were formed by magnetic stirring. The typical coating experiments were performed according to our previous work [3], the specific conditions were described as following, the $\mathrm{C}_{(\mathrm{NaOH})}$ was $0.5 \mathrm{~mol} / \mathrm{L}$ and the molar ratio of $\mathrm{C}_{\left(\mathrm{Fe}^{3+}\right)}: \mathrm{C}_{\left(\mathrm{Fe}^{2+}\right)}$ was kept at 1.6:1 under the conditions $\mathrm{pH} 9.2$ and temperature $30^{\circ} \mathrm{C}$ in $\mathrm{N}_{2}$ atmosphere, magnetic stirring at $130 \mathrm{r} / \mathrm{min}$. Then, the final product was filtrated, washed and dried at $60{ }^{\circ} \mathrm{C}$, calcined for 3 hours at $350{ }^{\circ} \mathrm{C}$.

\subsection{Coating layer characterization}

The coating percentage of $\mathrm{Fe}_{3} \mathrm{O}_{4}$ coatings on the surface of the micron Glass were determined as previously described [3] by external standard calibration method.

\section{Results and Discussion}

\subsection{Measurements of the coating percentage of $\mathrm{Fe}_{3} \mathrm{O}_{4}$ on surface}

The XRD patterns of pure glass, pure $\mathrm{Fe}_{3} \mathrm{O}_{4}$ and sample were shown in Figure 1. As can be seen, diffraction peak of pure micro glass is only a wide peak and there is no silica crystal line, demonstrating that glass powder is just a vitreous. The diffraction peaks of the chosen in the experiment $\mathrm{Fe}_{3} \mathrm{O}_{4}$ appeared at $2 \theta$ $=30^{\circ}, 35.4^{\circ}, 43.1^{\circ}, 53.7^{\circ}, 57.1^{\circ}$ and $62.8^{\circ}$, corresponding to $2.98 \AA$ (220), $2.53 \AA$

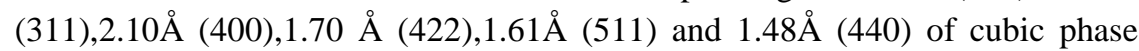
$\mathrm{Fe}_{3} \mathrm{O}_{4}$ respectively. After micro glass was coated by $\mathrm{Fe}_{3} \mathrm{O}_{4}$, the diffraction peaks of the sample appeared at $2 \theta=30^{\circ}, 35.5^{\circ}, 43.1^{\circ}, 57.1^{\circ}$ and $62.8^{\circ}$, corresponding to the characteristic diffraction peak (220), (311), (400), (511) and (440) of $\mathrm{Fe}_{3} \mathrm{O}_{4}$, indicating $\mathrm{Fe}_{3} \mathrm{O}_{4}$ has been coated on the micro glass surface. 
The content of $\mathrm{Fe}_{3} \mathrm{O}_{4}$ can be calculated by using external standard calibration method [4]. $\mathrm{H}_{\mathrm{s}}$ and $\mathrm{H}_{\mathrm{i}}$ represent the peak intensity of glass and $\mathrm{Fe}_{3} \mathrm{O}_{4}$ respectively, $\mathrm{C}_{\mathrm{s}}$ and $\mathrm{C}_{\mathrm{i}}$ represent mass concentration of glass and $\mathrm{Fe}_{3} \mathrm{O}_{4}$, respectively. Related equations are as follows:

$$
\frac{H_{i}}{H_{S}}=F \cdot \frac{C_{i}}{C_{S}}
$$

Where $\mathrm{F}$ is the proportional coefficient,
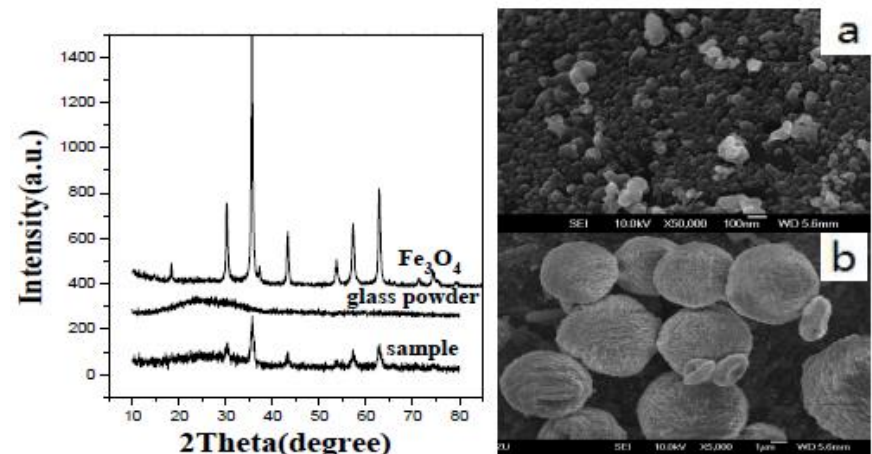

Fig. 1. XRD pattern and HRSEM of micro glass, Fe3O4, sample.

The corresponding peak intensity of the six standard samples was examined, using the strongest characteristic peak of $\mathrm{Fe}_{3} \mathrm{O}_{4}(311)$ as the main base peak. It is found that the normalized XRD peak (311) intensity was directly proportional to the mass ratio of pure $\mathrm{Fe}_{3} \mathrm{O}_{4}$ to micro glass, and thus the standard curve was plotted by normalized XRD peak (311) intensity versus percent of coated $\mathrm{Fe}_{3} \mathrm{O}_{4}$ to determine the percent of coated $\mathrm{Fe}_{3} \mathrm{O}_{4}$ in the sample.

The coating percent and colorimetric parameters of $\mathrm{Fe}_{3} \mathrm{O}_{4}$ prepared in experiments under different condition are given in Table 1.

Table 1. Colorimetric Parameters and $\mathrm{Fe}_{3} \mathrm{O}_{4}$ Coat Percent of the Coated Samples prepared under different eroding time of hydrofluoric acid solution, when $\mathrm{t}=30{ }^{\circ} \mathrm{C}$,

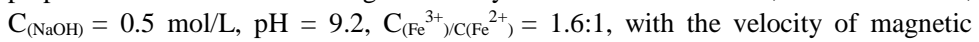
stirring being $113 \mathrm{r} / \mathrm{min} \leq \mathrm{v} \leq 149 \mathrm{r} / \mathrm{min}$ in the coating process

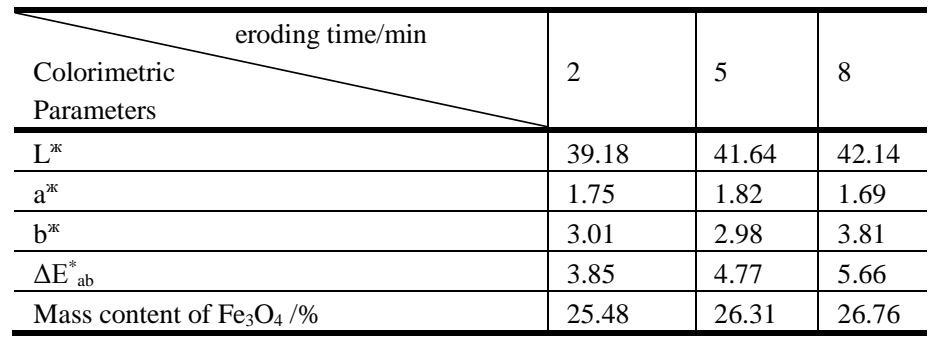


The standard colorimetric parameters were determined: $\mathrm{L}^{*}=38.80, \mathrm{a}^{*}=$ $+0.39, \mathrm{~b}^{*}=-0.57$, and colorimetric parameters of various synthesized samples determined under different conditions are listed in Table 1.

It is noted from the results of Table 1, all the luminance values $\mathrm{L}^{*}$ of $\mathrm{Fe}_{3} \mathrm{O}_{4}$ coating layer on micro glass were higher than that of the black ferric oxide pigment standard substance produced by the German Baier Pigment, Ltd. Co. The $\Delta \mathrm{E}^{*}{ }_{\mathrm{ab}}$ value was above 3 , showing obvious pearly luster effect.

\subsection{Effect of eroding time by hydrofluoric acid solution on coating performance of the micron glass surface}

The micron glass was treated by $0.5 \mathrm{~mol} / 1 \mathrm{NaOH}$ solution for $20 \mathrm{~min}$, and following eroded by $0.1 \mathrm{~mol} / \mathrm{L} \mathrm{HF}$ for $2 \mathrm{~min}, 5 \mathrm{~min}$ and $8 \mathrm{~min}$, respectively. The results showed the $\mathrm{Fe}_{3} \mathrm{O}_{4}$ coated layer with erosion at 8 min displays uniform packed nano-scales granular shape, with the size about $30 \mathrm{~nm}$.

Pearlescent effect is also based on the "growing points" of micro glass which is affected by eroding time of HF solution; if the eroding time is short, the nano- $\mathrm{Fe}_{3} \mathrm{O}_{4}$ particles cannot deposit uniformly on the micro glass, so lead to less "growing points" serving as "crystal seed point" for $\mathrm{Fe}_{3} \mathrm{O}_{4}$ precipitation. When eroding time reached $8 \mathrm{~min}$, the redness showed minimum value, while the yellowness and luminance value $\left(\mathrm{L}^{*}\right)$ showed the maximum value in the Table 1, and this led to the highest $\Delta \mathrm{E}^{*}{ }_{\mathrm{ab}}$ value, producing obvious effects of pearly luster. The $\mathrm{Fe}_{3} \mathrm{O}_{4}$ coating content was also observed to get maximum value, because more "growing points" serve as "crystal seed point" for $\mathrm{Fe}_{3} \mathrm{O}_{4}$ precipitation.

In comparison with $\mathrm{Fe}_{3} \mathrm{O}_{4}$ coatings eroded by $\mathrm{NaOH}$ solution $(0.5 \mathrm{~mol} / \mathrm{l})$, the obvious improvements can be observed. But smoothness of coatings is not so desirable, in order to improve homogeneity and density of the coatings further, the increase of temperature for $\mathrm{Fe}^{3+}$ and $\mathrm{Fe}^{2+}$ co-precipitation must be considered first, because high temperature is beneficial to the formation of $\mathrm{Fe}_{3} \mathrm{O}_{4}$ [2].

\subsection{Effect of co-precipitation temperature on coating performance of the micron glass surface}

The co-precipitation temperature played important role on the pearlescent effect of samples, as shown in Table 1. With the temperature increasing, the yellowness and luminance value $\left(\mathrm{L}^{ж}\right)$ decreased, and the redness showed minimum value at $90^{\circ} \mathrm{C}$, this led to the highest $\Delta \mathrm{E}^{*}$ ab value of 9.73 and 9.21 at 85 and $90^{\circ} \mathrm{C}$ respectively, producing obvious effects of pearly luster. It is probable because the microspheres of $\mathrm{Fe}_{3} \mathrm{O}_{4}$ coated glass prepared at $90^{\circ} \mathrm{C}$ had the most smooth and compact coating.

The images recorded in Figure 1(a) showed uniform tightly packed granules 
about $40 \mathrm{~nm}$ in diameter, and the coating layer on the micron glass surface was relatively smooth and compact. Figure 1(b) was the image of the microspheres of $\mathrm{Fe}_{3} \mathrm{O}_{4}$ coated glass at $90{ }^{\circ} \mathrm{C}$, it can be seen that $\mathrm{Fe}_{3} \mathrm{O}_{4}$ coatings were smooth and compact, the very fine $\mathrm{Fe}_{3} \mathrm{O}_{4}$ crystals packed closely on substrates to form micro-scale spherical granules with the mean diameter about $5.8 \mu \mathrm{m}$, indicating the optimum coating process should be performed according to following steps. The substrates were treated by $0.5 \mathrm{~mol} / \mathrm{L} \mathrm{NaOH}$ solution for $20 \mathrm{~min}$, following eroded by $0.1 \mathrm{~mol} / \mathrm{L} \mathrm{HF}$ solution for $8 \mathrm{~min}$, and finally coated by $\mathrm{Fe}_{3} \mathrm{O}_{4}$ at $90^{\circ} \mathrm{C}$. The synthetic process should minimize long and short-term impacts on the environment [5].

\section{Conclusions}

In this experiment, pearlescent pigment was prepared by deposition of nano$\mathrm{Fe}_{3} \mathrm{O}_{4}$ on the micron glass surface by "crystal seed point" growing method. The effects of eroding time on micro glass surface by hydrofluoric acid, and effect of co-precipitation temperature on $\mathrm{Fe}_{3} \mathrm{O}_{4}$-coated glass morphology were discussed. The results showed when the micro glass as a substrate would be eroded by $0.5 \mathrm{~mol} / \mathrm{l}$ sodium hydroxide solution for $20 \mathrm{~min}$ and then by $0.1 \mathrm{~mol} / \mathrm{L}$ hydrofluoric acid for $8 \mathrm{~min}$, the more "growing points" for "crystal seed point" of $\mathrm{Fe}_{3} \mathrm{O}_{4}$ can be provided. XRD analysis demonstrates that the $\mathrm{Fe}_{3} \mathrm{O}_{4}$ has been coated on the micro glass surface.

\section{References}

1. E.J.W. Verwey, Electronic conduction of magnetite (Fe3O4) and its transition point at low temperatures, Nature, 144, 327 (1939).

2. X.J. Liang, H.Q. Xu, J. Chen, J.C. Sun, Y.X. Yang, and X.N. Liu, Research of Mica/Fe3O4 Pearlescent Pigment by Co-Precipitation, Glass Phys. Chem., 37, 330 (2011).

3. Y.H. Hu, Z.J. Wang, Mechanism of Glass Frosting, Galss \& Ceram. 18, 37 (1990).

4. Z.X. Xie, Z.L. Zhao, Y.B. Zhang and Y.P. Chen, X-ray spectrum analysis (Science Press, China, 1982).

5. M. Titirici, Robin.J. White, C. Falco and M. Sevilla, Black perspectives for a green future: hydrothermal carbons for environment protection and energy storage, Energy Environ. Sci., 5, 6796 (2012). 